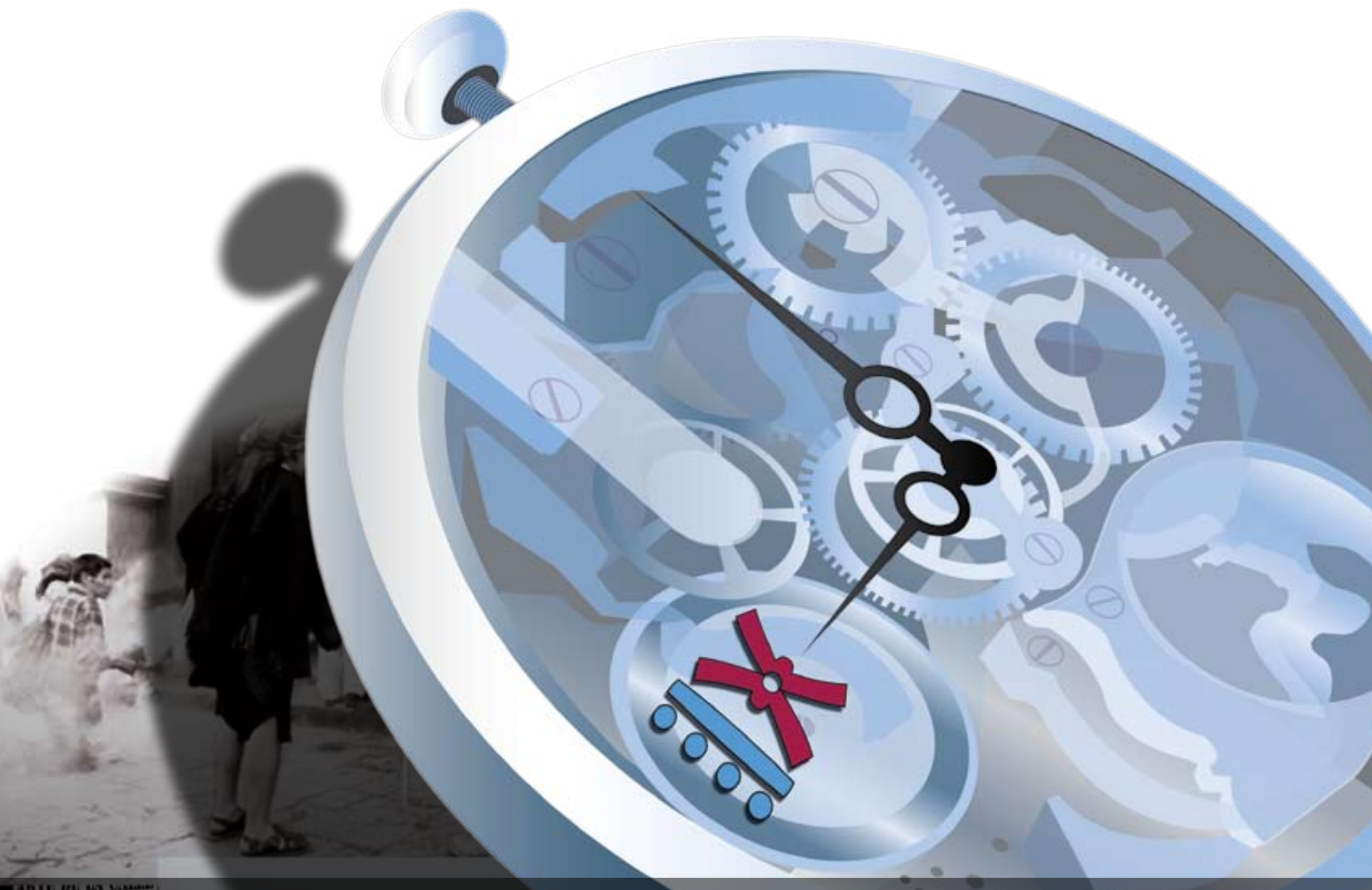

$9^{\circ}$ CONGRESO 2. CENTROAMERICANO DE HISTORIA

Universidad de Costa Rica ISSN 1409-469X

Fecha de recepción: 15 de mayo 2008 Fecha de aceptación: 30 de mayo 2008

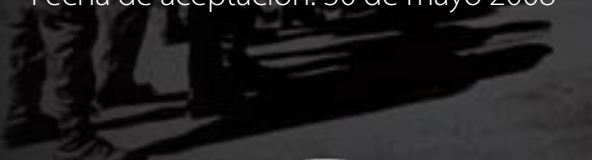

El Primer Seminario Regional de la Comisión Interamericana de Mujeres (CIM), San Salvador (1951)

Miembros del Consejo Editorial:

Dr. Ronny Viales, Dr. Juan José Marín

Editores Técnicos:

Allan Fonseca, Andrés Cruz, Gabriela Soto
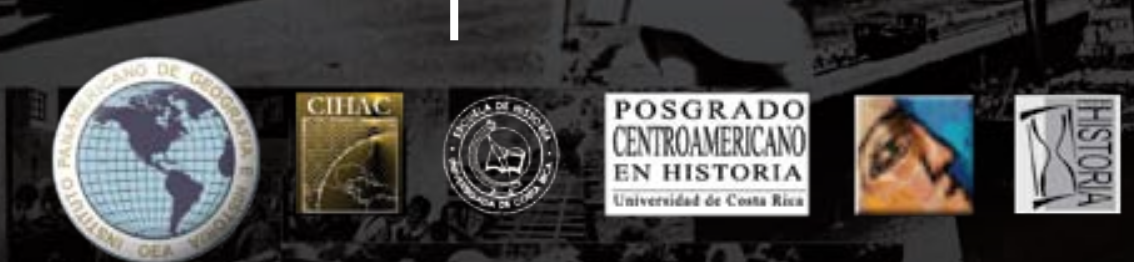
Indexaciones: Repositorio de Revistas UCR, DIALNET, Latindex, REDALYC Directorio y recolector de recursos digitales del Ministerio de Cultura de España, Directory of Open Access Journals. Diálogos Revista Electrónica de Historia ISSN 1409-469X. Número especial 2008. Dirección web: http://historia.fcs.ucr.ac.cr/dialogos.htm

\title{
El Primer Seminario Regional de la Comisión Interamericana de Mujeres (CIM), San Salvador (1951)
}

Dra. Guadalupe Rodríguez de Ita

\author{
Instituto de Investigaciones Dr. José Ma. Luis Mora \\ Plaza Valentín Gómez Farías No. 12 \\ Col. San Juan Mixcoac, México, D. F. 03730, México \\ Tel. (52 55) 55983777 \\ Fax (52 55) 55637162 \\ E-mail: gri@mora.edu.mx
}




\title{
“El Primer Seminario Regional de la Comisión Interamericana de Mujeres (CIM), San Salvador (1951)”
}

\author{
Dra. Guadalupe Rodríguez de Ita \\ Instituto de Investigaciones Dr. José Ma. Luis Mora \\ México, México D.F.
}

\section{Introducción}

La Comisión Interamericana de Mujeres (CIM), organismo multiestatal, surgido en 1923 y vigente hasta nuestros días, ha desarrollado a lo largo de su existencia diversas iniciativas y acciones encaminadas a conocer y mejorar la situación de las mujeres del continente americano, así como a que se reconozcan y respeten los derechos femeninos en dicha zona. Tales iniciativas y acciones, si bien no han sido cabalmente contundentes, en buena medida por falta de voluntad política de los Estados miembros de la Unión Panamericana y de la Organización de Estados Americanos, si han tenido su impacto en las sociedades de este hemisferio. De allí que sea importante estudiar este organismo y sus actividades.

Entre ellas se tiene justamente el seminario regional del que se ocupa esta ponencia, cuyo objetivo es efectuar un primer acercamiento a las reivindicaciones, los debates y las recomendaciones que tuvieron lugar en el seno de ese seminario, celebrado en San Salvador, entre el 15 de enero y el 3 de febrero de 1951, en el que participaron representantes de Estados Unidos, México y Centroamérica. 
Dicho acercamiento está basado fundamentalmente en la documentación consultada en el Archivo Histórico "Genaro Estrada" de la Secretaría de Relaciones Exteriores de México, en donde se han ubicado importantes informes rendidos por las participantes del seminario, así como notas de prensa con las que se ha podido reconstruir, salvo algunos pequeños detalles, gran parte del proceso de este seminario.

\section{Preparativos y objetivos}

La CIM, de acuerdo con su Estatuto aprobado en la IX Conferencia de Bogotá de 1948, tenía entre sus funciones la de trabajar por la extensión a la Mujer de América de los Derechos Civiles, Políticos, Económicos y Sociales; estudiar sus problemas y proponer medidas para resolverlos. ${ }^{1}$ Sobre esa base, su Comité Directivo resolvió aprobar la propuesta, presentado por la presidencia de la $\mathrm{CIM},{ }^{2}$ de organizar seminarios regionales en América, cuyo objetivo central era examinar la situación de las mujeres en los distintos países del continente, ${ }^{3}$ así como discutir alternativas para, según el caso, mantener y/o mejorar tal situación con el concurso de las propias mujeres, 1 Amalia de Castillo Ledón, presidenta de la CIM, "El Primer Seminario Regional de la Comisión Interamericana de Mujeres (15 de enero al 3 de febrero de 1951, El Salvador)", sin lugar (s.1.), sin fecha (s.f.), en Archivo Histórico "Genaro Estrada" de la Secretaría de Relaciones Exteriores de México (AHGE-SREM)/Archivo Personal de Amalia de Castillo Ledón (APACL), Expedientes (Exps.) 207 y 219; María Lavalle Urbina, presidenta de la delegación mexicana al Primer Seminario Regional de la CIM, "Informe de las actividades realizadas por la delegación mexicana al Primer Seminario Regional de la Comisión Interamericana de Mujeres", México, D. F., 20 de febrero de 1951, en AHGE-SREM, Exp. III-2082-1; Amalia de Castillo Ledón, presidenta de la Comisión Interamericana de Mujeres (CIM), a Neftalí Ponce, ministro de Relaciones Exteriores de Ecuador, s.l., 13 abril de 1951, en AHGE-SREM/APEACL, Exp. 221.

2 La presidencia de la CIM estaba encabezada entonces por la mexicana Amalia de Castillo Ledón. Amalia de Castillo Ledón, "Saludo a las mujeres y organizaciones de América, Boletín de la CIM, 1949”, en Comisión Interamericana de Mujeres, Historia de la Comisión Interamericana de Mujeres (CIM) 1928-1997 (Washington, Comisión Interamericana de Mujeres, 1998), 231-232.

3 de Castillo Ledón a Ponce. 
de organizaciones diversas y, desde luego, de los gobiernos de cada Estado.

Con los seminarios se buscaba además establecer vínculos no sólo con esos actores, sino también con la prensa, los intelectuales y con la población en general para que conocieran las labores de la CIM. ${ }^{4}$

De esta manera, planearon inicialmente la realización de tres seminarios regionales: el primero comprendía las zonas del norte y del centro del continente; el segundo, las Antillas y el norte de Sudamérica; y el tercero, el resto de esta última región. ${ }^{5}$

\section{Organización y agenda}

Hacia mediados de $1950,{ }^{6}$ empezó a organizarse el primer seminario regional que, como se anotó, abarcaba el norte y el centro de América.

Con la finalidad de cumplir con el objetivo central del mismo, se elaboró una agenda en la que se plantearon cuatro temas generales: el civil, el político, el económico-social y el educativo; ${ }^{7} \mathrm{y}$, dentro de cada uno de ellos, varios subtemas (véase Anexo 1).

Para su funcionamiento se decidió dividir el seminario, por una parte, en sesiones de mesa redonda o de grupo por cada uno de los temas y, por otra, en plenarias. ${ }^{8}$

4 de Castillo Ledón, "El Primer Seminario"; Amalia de Castillo Ledón, "Discurso de la Señora Amalia de Castillo Ledón, presidenta de la Comisión Interamericana de Mujeres, en el acto de inauguración del Primer Seminario Regional de la CIM, San Salvador, El Salvador, Enero 15, 1951", s.l., s.f., en AHSRE-SREM/APACL, Exp. 219.

5 de Castillo Ledón, "El Primer Seminario".

6 Amalia de Castillo Ledón, presidenta de la CIM, a María (Lavalle Urbina), s.1., 25 de mayo de 1950, en AHGE-SREM, Exp. III-2082-1; Amalia de Castillo Ledón, presidenta de la CIM, a Manuel Tello, subsecretario de Relaciones Exteriores de México, s.1., 3 de noviembre de 1950, en AHGE-SREM, Exp. III-2082-1.

7 de Castillo Ledón, "El Primer Seminario"; "Se da a conocer la agenda del Primer Seminario Regional de la Comisión Interamericana de Mujeres" en Diario Latino, San Salvador, 11 de diciembre de 1950, en AHSRESREM, Exp. III-2082-1; Lavalle Urbina, "Informe de las actividades".

8 de Castillo Ledón, "El Primer Seminario". 
Con vistas a "encauzar los trabajos por senderos precisos, evitando la dispersión y ahondando en los problemas"9 y poder obtener información verídica y actualizada sobre la cual la misma CIM, las propias mujeres, las diversas organizaciones y los gobiernos pudieran iniciar acciones tendientes a "la eliminación de leyes o de prácticas que, jurídicamente o de hecho, interfieran con el avance de la mujer y su total integración a la vida colectiva", ${ }^{10}$ con la cooperación de delegadas de Estados Unidos y de Costa Rica, y con la asistencia técnica de algunas dependencias de la Unión Panamericana, la CIM preparó con anticipación amplios cuestionarios sobre cada uno de los temas y subtemas. ${ }^{11}$

\section{Realización y participantes}

Después de algunas vicisitudes, el primer seminario regional de la CIM se celebró del 15 de enero al 3 de febrero de 1951, en San Salvador (El Salvador).

Para su realización, la CIM contó con la simpatía y el apoyo de la Unión Panamericana, de varios Estados americanos y, sobre todo, del gobierno y la sociedad del país anfitrión. ${ }^{12}$ Muestra de esto último fueron las atenciones y las numerosas recepciones organizadas, para las delegadas, por los ministerios de Relaciones Exteriores, de Cultura y de la Defensa Nacional, así como por parte del Comité Social de Cooperación para la organización del seminario. ${ }^{13}$ También se evidenció en "la asistencia nutrida y constante de mujeres [salvadoreñas] de todas las clases sociales que asistían diariamente a las sesiones y seguían las deliberaciones con marcado interés [...]". ${ }^{14}$

9 Lavalle Urbina, "Informe de las actividades".

10 de Castillo Ledón, "El Primer Seminario".

11 Ibid.

12 Ibid.

13 Lavalle Urbina, "Informe de las actividades". El Comité Social de Cooperación para la organización del Seminario estuvo encabezado por la salvadoreña Carmela Vilanova.

$14 \quad$ Ibid. 
El seminario tuvo dos sesiones solemnes: una de apertura y la otra de clausura, a ellas concurrieron la entonces primera dama del país, los ministros de Relaciones Exteriores y de Cultura y otros altos funcionarios salvadoreños, así como el cuerpo diplomático. También se realizaron tres plenarias, a ellas acudieron diplomáticos, lo mismo que el ministro de la Defensa Nacional y así como hombres y mujeres de la sociedad salvadoreña. Además se desarrollaron 12 sesiones de mesa redonda, donde debatieron las delegadas acreditadas y otras cuatro dedicadas a las

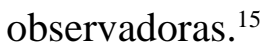

Participaron en el seminario un total de 39 representantes oficiales de seis de los ocho países convocados, donde sólo Guatemala y Panamá no enviaron ninguna delegada, en tanto que El Salvador nombró al número más elevado. Cada delegación contaba con una coordinadora o jefa que, en general, era la representante del país respectivo ante la CIM (véanse Cuadro 1 y Anexo 2).

Además de las delegadas oficiales, asistieron varios técnicos, hombres y mujeres, de la Unión Panamericana; ${ }^{16}$ asimismo, concurrieron 142 observadoras en representación de diversas organizaciones y grupos salvadoreños de mujeres, tales como: profesionistas, trabajadoras sociales, enfermeras, maestras, costureras, campesinas, etc. Dichas observadoras formalmente no tenían ni voz ni voto; sin embargo, considerando la importancia de cambiar impresiones con ellas, cada grupo de trabajo dedicó una sesión especial para escuchar sus puntos de vista y sus sugerencias sobre los temas de estudio. ${ }^{17}$

$15 \quad$ Ibid.

16 Radar, "Etcétera. Isidro de la Torre, Grave" en Excélsior, México, D. F., 12 de enero de 1951 en AHGE-SREM/APACL, Exp. 222.

17 de Castillo Ledón, "El Primer Seminario". 


\section{Debates, conclusiones y recomendaciones}

\subsection{Aspecto civil}

Las delgadas de la mesa redonda encargada del aspecto civil, ${ }^{18}$ realizaron un examen comparativo de la legislación sobre esa materia en cada uno de los países de la región. Para ello, como primer paso, buscaron contestar a las preguntas del cuestionario, que les fue entregado previamente, entre cuyas interrogantes estaban las siguientes, en algunos casos con su respuesta:

1.- Principios generales:

a) ¿A qué edad entra la mujer de su país en el pleno goce de sus derechos civiles?

Existe unanimidad en las legislaciones de Honduras, El Salvador, Nicaragua, México, Costa Rica y los Estados Unidos, en el sentido de señalar los 21 años.

b) ¿Es ella, desde el punto de vista jurídico, igual al hombre?

En El Salvador, no, salvo ciertas excepciones.

En Estados Unidos, la mujer es igual al hombre en todos los derechos civiles, siendo soltera; pero después del matrimonio, pierde varios de esos derechos.

En México y Costa Rica el Código Civil otorga los mismos derechos al hombre que a la mujer.

4.- Domicilio de la mujer

a) ¿Podría la mujer soltera, siendo menor, abandonar por razones justificadas el domicilio de sus padres? ¿Cuáles serían esas razones?

En El Salvador, Honduras y Nicaragua: no podría.

En Estados Unidos, por razones morales, la Corte puede tomar a la criatura y darle un guardián; y es en esencia el mismo caso de Costa Rica, en donde los parientes o el Patronato Nacional de la

18 Radar. La mesa estuvo presidida por la mexicana María Lavalle Urbina. 
Infancia, solicita al Juez el depósito legal del menor.

En México, en términos generales, no; pero sí podría hacerlos por razones justificadas ante el Juez y con autorización de este.

b) ¿Puede la mujer casada escoger o cambiar su domicilio por voluntad propia?

El Salvador: en términos generales si, salvo cuando es menor de 18 años.

Costa Rica: generalmente no, pero cuando tenga motivos que den mérito a divorcio, puede solicitar autorización judicial para cambiar de domicilio.

Honduras, Nicaragua y Estados Unidos, no; salvo el caso de que le ocasione grave perjuicio, a juicio del Juez. ${ }^{19}$

De esa manera, analizaron los problemas relativos a la edad en que las mujeres empezaban a ejercer sus derechos civiles, a la emancipación, la nacionalidad, el domicilio, el patrimonio, el compromiso matrimonial, el matrimonio, la autorización marital, el divorcio, la separación de cuerpos, las pensiones alimenticias, los derechos sobre los hijos, la filiación, la adopción, la patria potestad, la tutela y la curatela. ${ }^{20}$

Luego del estudio de la situación, en donde encontraron gran similitud en los países participantes, ${ }^{21}$ discutieron y acordaron alrededor de treinta sugerencias para la reforma de los códigos civiles. De ellas, tres giraron en torno a la igualdad de derechos y a la emancipación; nueve a compromiso matrimonial y matrimonio, nueve sobre divorcio; siete sobre adopción, patria potestad y tutela; y

19 "Resoluciones importantes del Primer Seminario Internacional de Mujeres", en Orientación Social, San Salvador, 3 de febrero de 1951 en AHGE-SREM, Exp. III-2082-1.

20 María Lavalle Urbina, delegada de México al Seminario Regional de la CIM, "Primer aspecto del temario. Mesa redonda de derechos civiles", s.1., s.f., en AHGE-SREM, Exp. III2082-1.

21 Víctor Alfonso Maldonado, embajador de México en El Salvador, a Secretaría de Relaciones Exteriores de México, San Salvador, 18 de enero de 1951 en AHGE-SREM, Exp. Exp. III-2082-1. 
tres sobre ejercicio profesional. Entre tales sugerencias se pueden destacar:

PRIMERA. Que los ordenamientos jurídicos de El Salvador, Nicaragua y Honduras establezcan categóricamente que la mujer debe tener los mismos derechos civiles que el hombre, como se encuentra establecido en los Códigos de los otros países asistentes. La misma sugerencia correspondería a algunos estados, como Texas, de los Estados Unidos, en los que existen graves discriminaciones.

$[\ldots]$

SÉPTIMA. Que en todos los países asistentes se intensifique el matrimonio civil como medio para combatir el concubinato y la existencia de los hijos fuera del matrimonio.

$[\ldots]$

DÉCIMA PRIMERA. Que en El Salvador y Costa Rica. Se armonicen los Códigos Civiles con sus respectivas Constituciones Políticas en relación las disposiciones de estas últimas, que dicen que dentro del matrimonio los esposos tienen igualdad de derechos.

VIGÉSIMA PRIMERA. Que en el Salvador se suprima el adulterio como delito, quedando únicamente como causal de divorcio.

VIGÉSIMA SEGUNDA. Que en Nicaragua y Honduras en caso de adulterio se imponga igual pena para hombres y mujeres.

VIGÉSIMA SÉPTIMA. Que en El Salvador, Honduras y Nicaragua, sea ejercida la patria potestad de común acuerdo entre los cónyuges.

TRIGÉSIMA PRIMERA. Que en El Salvador y Honduras se consigne categóricamente que las mujeres pueden ejercer la abogacía y el notariado y en México se supriman todas las restricciones para el ejercicio de este último.

TRIGÉSIMA SEGUNDA. Que El Salvador, Honduras, México, Costa Rica y Nicaragua se dé 
participación a las mujeres en las asambleas legislativas para que puedan hacer sentir su influencia en la reforma de leyes y códigos.

COMO PROPOSICIÓN GENERAL PARA TOSOS LOS PAÍSES ASISTENTES se recomienda combatir el desconocimiento de las disposiciones legales que indican a la mujer, cuales son sus derechos y deberes, por medio de una amplia difusión de las disposiciones que al respecto contengas los códigos y demás leyes, a fin de que la mujer y en general los componentes de la sociedad los conozcan. Este deber corresponde fundamentalmente a los profesionales que deben utilizar todo medio a su alcance para cumplir esta tarea. ${ }^{22}$

\subsection{Aspecto político}

En la mesa redonda referente a la temática política, al igual que en las otras mesas, las delegadas efectuaron un estudio comparativo de la legislación sobre esa materia en cada uno de los países. ${ }^{23}$ Para ello, dedicaron una sesión para cada uno de los subtemas que consideraron más significativos, a saber: ciudadanía, sufragio, tribunales electorales y aportes de la mujer a la vida política y administrativa. ${ }^{24}$

Sobre el primer subtema, revisaron dos puntos que en general se estimaban -y se siguen estimandodeterminantes para ser consideradas como ciudadanas, como son el lugar de nacimiento y la edad; también examinaron otros puntos como el ejercicio, la suspensión y la recuperación de la ciudadanía. Acerca de ellos encontraron algunas similitudes y diferencias en los países de la región, como las siguientes:

1) Que en El Salvador el nacimiento no es determinante de la calidad de ciudadano. En los Estados Unidos el nacimiento determina la ciudadanía. En México y en Nicaragua el nacimiento es uno de

22 Lavalle Urbina, "Primer aspecto del temario".

23 Maldonado.

24 "Resoluciones importantes". 
los determinantes de la ciudadanía, aunque no el único.

En El Salvador, Estados Unidos, México y Nicaragua, de conformidad con el precepto constitucional, la mujer es ciudadano. En Honduras las mujeres no son ciudadanas.

2) En El Salvador y en los Estados Unidos, la mujer goza plenamente de sus derechos políticos, en el primer país a los 18 años y en el segundo a los 21 años. La mujer mexicana no goza plenamente de estos derechos, sin embargo existen Estados en que disfrutan de todos ellos.

3) Que la mujer de El Salvador ejerció por primera vez el sufragio en 1950, aunque ya desde 1939 el sufragio estaba concedido con restricciones. En los Estados Unidos la mujer obtuvo el sufragio en el año 1920. En México la mujer ha ejercido el sufragio municipal desde hace varios años.

4) En El Salvador, Estados Unidos, México y Nicaragua las mujeres pueden optar a todos los cargos públicos en idénticas condiciones que el hombre. En Honduras, como la mujer no es ciudadano, no puede hacerlo desde el punto de vista legal, pero en la práctica hay mujeres desempeñando estos cargos en el ramo educativo.

5) En El Salvador, Estados Unidos, México y Nicaragua se suspende y recobra la ciudadanía de la mujer por las mismas causales y por los mismos medios que el hombre. Estas causales, aunque varían un poco de un país a otro, son fundamentalmente las mismas. En Honduras no se suspende la ciudadanía de la mujer porque no goza de ella. ${ }^{25}$

\section{A partir de tal situación, plantearon las recomendaciones que se anotan a continuación:}

a) Trabajar porque se otorgue la ciudadanía a la mujer en aquellos países en que aún no la tienen, puesto que tal situación las deja prácticamente al margen de la vida nacional.

b) Luchar porque la mujer goce plenamente de sus derechos políticos no sólo en el texto de las leyes, sino en la realidad, en la vida diaria.

25 Ibid. 
c) Gestionar porque en igualdad de condiciones y capacidades la mujer pueda optar a los cargos públicos, a la par que el hombre. ${ }^{26}$

En los que respecta al segundo subtema, es decir, al del sufragio, analizaron, entre otras cuestiones: si el voto era pasivo o activo; también si éste permitía a las mujeres acceder a cargos públicos de elección popular, en que niveles y si en ello intervenían los partidos políticos; incluso estudiaron, pese a no tener relación tan directa con el sufragio, si las mujeres habían desempeñado cargos en el servicio exterior de su país. Sobre estas cuestiones hallaron especificidades interesantes por países, como las siguientes:

1) La mujer ejerce el sufragio activo en El Salvador y Estados Unidos. Solamente en México ejerce la mujer el sufragio municipal. En Honduras lo ejerció en 1928 en el Departamento de Choluteca, pero la Constitución siguiente las privó de este derecho que ya habían adquirido. No ha habido mujeres munícipes en El Salvador ni en Nicaragua, tampoco en Honduras. En Estados Unidos y en México, si ha habido mujeres munícipes. [...]

En los países en que la mujer ejerce el sufragio femenino lo hace en las mismas condiciones que el hombre.

2) Para inscribirse en los registros electorales se exige a la mujer, en aquellos países en que ejerce el voto activo, los mismos requisitos que al hombre y por los mismos organismos electorales.

3) En los países constituidos federalmente, Estados Unidos y México, existen diferencias de un Estado a otro en cuanto a los derechos otorgados a la mujer, pero no existe un solo Estado que niegue totalmente estos derechos a la mujer.

4) En El Salvador no ha habido mujeres con cargos de importancia en el servicio diplomático ni en el consular. En México, Estados Unidos y Nicaragua, desde hace muchos años, la mujer

\section{$26 \quad$ Ibid.}


ha desempeñado cargos en el servicio Diplomático y consular. En Nicaragua hay actualmente 5 mujeres en el servicio consular y 2 en el diplomático. En Honduras hay 2 mujeres en el servicio diplomático.

5) La mujer ha participado activamente, en la mayor parte de los países, dentro de los partidos políticos, pero no ha obtenido postulaciones o candidaturas. ${ }^{27}$

\section{Con esos datos, hicieron varias sugerencias:}

a) Luchar por la obtención del sufragio femenino en los países que aún no lo tienen y que se dicten leyes reglamentarias en aquellos en que el principio de sufragio femenino ya está consignado en la carta fundamental.

b) Influir dentro de los partidos políticos respectivos para que se postulen candidaturas de mujeres.

c) Pedir a los gobiernos que se dé oportunidad a muchas mujeres capacitadas a desempeñar cargos de importancia en el servicio exterior.

d) Trabajar por la preparación o especialización de las mujeres en la carrera de servicio exterior, mediante la obtención de becas que le permitan hacer estudios en el extranjero. ${ }^{28}$

Respecto al último punto, el de los aportes de la mujer a la vida política y administrativa, hicieron un recuento bastante detallado, en el que vislumbraron una serie de problemas y carencias que, por considerarlo de importancia, se cita in extenso:

1) Que en la mayoría de nuestros países las mujeres han contribuido eficientemente a la vida política y participado en las campañas electorales, aportando energías, entusiasmo, trabajo y dinero para el triunfo de los partidos, aún en aquellos países en que la mujer no ejerce el sufragio activo.

\section{$27 \quad$ Ibid.}

28 Ibid.


2) Que la mujer en idénticas condiciones que el hombre ha contribuido en cada país al pago de contribuciones ordinarias. La delegada de los Estados Unidos hace notar que el 70\% de los capitales de su país está en manos de mujeres.

3) Que aunque en la mayor parte de nuestros países no hay restricciones constitucionales para que las mujeres integren los poderes públicos, en la práctica no se cumple este precepto. Excepción debe hacerse de los Estados Unidos que tienen mujeres en los tres poderes, Nicaragua que tiene mujeres en el Ejecutivo y el Judicial, Costa Rica en el Ejecutivo y México en el Judicial.

4) Ninguna mujer, en ninguno de los países representantes en el Seminario, ha intervenido en la redacción de las respectivas Constituciones y por lo tanto no llevan firma de mujer estos trascendentales documentos.

5) Actualmente sólo tres países tiene representativas mujeres en el gabinete:

Estados Unidos: Mrs. Anna Rosenberg, Sub-Secretaria de Defensa.

Nicaragua: Dra. Olga Núñez Abaúnza, Vice-Ministro de Educación Pública.

Costa Rica: Srita. Emma Gamboa, Sub-Secretaria de Educación Pública.

Las dos primeras se encuentran en el ejercicio de sus respectivos cargos. La Srita. Gamboa, ha sido nombrada, pero no ha tomado posesión ni ejercido su cargo, por encontrarse en los Estados Unidos realizando estudios.

6) Que el principal obstáculo que la mujer ha encontrado en su lucha por incorporarse a la vida política nacional, es el egoísmo del hombre, el prejuicio y las tradiciones de nuestros pueblos. Que el principal argumento que se esgrime contra su participación en los asuntos públicos es que 
se necesita preparación especial. Pudiendo oponerse a tal razonamiento que tampoco se exigió al hombre preparación especial para participar en estas actividades, como el sufragio por ejemplo; que la práctica es la mejor escuela y que es absurdo que miles de hombres que no saben ni leer ni escribir puedan ejercer estos derechos cuando muchas mujeres de gran preparación y mentalidad no pueden hacerlo. ${ }^{29}$

Para avanzar en la superación de éstos propusieron acciones como las siguientes:

a) Gestionar porque se deroguen las disposiciones que impiden a la mujer el acceso al poder Ejecutivo y al Judicial en aquellos países en que tales disposiciones existan. También que donde no haya tales restricciones ni obstáculos la mujer en la realidad integre esos poderes.

b) Luchar porque las mujeres lleguen a formar parte del poder Legislativo, haciendo uso de los derechos que al efecto le otorgan las mismas leyes; ya que es el poder Legislativo por medio del cual se pueden reformar las legislaciones secundarias que impiden que las conquistas constitucionales de la mujer se lleven a la práctica.

$[\ldots] .^{30}$

Además de las recomendaciones particulares para cada punto del aspecto político abordado en esta mesa redonda, hicieron otra más general que, por su significación y hasta vigencia, se anota in extenso:

Que los medios más EFICACES Y RECOMENDABLES PARA CONSEGUIR LA TOTALIDAD

DE LOS DERECHOS POLÍTICOS en aquellos países en que aún no han sido conquistados por la mujer, son los siguientes:

$29 \quad$ Ibid.

$30 \quad$ Ibid. 
La realización de una campaña vigorosa, organizada y unificada, auspiciada por las organizaciones femeninas del país, sin discriminación alguna. Tal campaña deberá comprender no sólo las gestiones del caso ante las autoridades gubernamentales respectivas, sino un esfuerzo por elevar el nivel cultural de la mujer, por reducir el alarmante porcentaje de analfabetismo femenino, por divulgar entre la mujer el conocimiento de sus derechos y de las leyes que la benefician.

Para tales efectos, serían medios efectivos: la organización de cursos de educación cívica para mujeres adultas; la edición y distribución de cartillas políticas, redactadas en un lenguaje sencillo y comprensible para que estén al alcance de todas las mujeres; la fundación en cada país, por lo menos, de una diario o revista que defienda la causa de la mujer.

Interesar en la realización de esta campaña, no sólo a los círculos de mujeres intelectuales, sino a la mujer obrera, a la campesina, clases de enorme potencialidad, sin la participación o el respaldo de las cuales ninguna transformación social es posible o permanente. $[\ldots]]^{31}$

\subsection{Aspecto económico-social}

Las delegadas de la mesa redonda encargada del aspecto económico y social ${ }^{32}$ empezaron su trabajo basándose en la agenda y el cuestionario que les fueron proporcionados previamente.

31 Ma. Elena Ramírez, delegada de México al Seminario Regional de la CIM, "Segundo aspecto del temario. Mesa redonda de derechos políticos", s.l., s.f., en AHGE-SREM, Exp. III2082-1.

32 Isabel Farfán Cano, "Conclusiones de mesa redonda sobre los problemas económico-sociales (especial para los periódicos Lozano, VI)", Magazín dominical de los periódicos Lozano, s.l., 20 de mayo de 1951 en AHDREM/APACL, Exp. 222. Esta mesa estuvo presidida por Mary Cannon, representante de Estados Unidos; como secretaria se nombró a la licenciada Gertrudis Bográn de Cuell, de Honduras; y como relatora a la enfermera Mélida Luz Palacios, de El Salvador; las demás integrantes fueron: Eva Alcaine de Palomo, Luz de Pacas Moreno, Angélica de Najarro y Carmen Vilanova de Alfaro, por El Salvador; María Teresa Dedengo, por Costa Rica; y Gudelia Gómez y Esperanza Colín Carrillo por México. 
Así, entre las preguntas y respuestas surgidas en la primera sesión, dedicada a las empleadas fiscales u oficiales, estuvieron las siguientes:

1. ¿Cuál es el número de mujeres empleadas fiscales?

HONDURAS: Aproximadamente tiene 2,500 empleadas fiscales.

EL SALVADOR: Aproximadamente 5,000.

MÉXICO: Un total de 150,000 y en el Distrito Federal 35,000.

Varios de los países participantes no pudieron precisar la proporción de mujeres en relación con los hombres, por falta de datos estadísticos. Estos datos podrán precisarse después que se conozcan los resultados del censo de 1950 .

2. ¿Existe alguna ley que limite el trabajo de las mujeres en ciertas reparticiones públicas? ¿Por cuáles razones?

HONDURAS: No hay restricciones en cuanto a sexo.

MÉXICO y EL SALVADOR: tampoco existen restricciones en cuanto a sexo.

En los tres países citados anteriormente los altos puestos administrativos son ocupados, en su mayoría por hombres.

ESTADOS UNIDOS no hay discriminación legal de sexo. Cada jefe puede elegir su personal, después de haber sido seleccionado por la comisión de Servicio Civil.

3- ¿Cuáles son los requisitos mínimos para ocupar un cargo público?

HONDURAS: Ser ciudadano.

MÉXICO: Ser mexicana, mayor de edad y estar capacitada para el cargo. Existe el Instituto de capacitación y exámenes. El ascenso se establece por escalafón y por antigüedad.

EL SALVADOR: Ser ciudadano. Tener capacidad reconocida. 
ESTADOS UNIDOS: El gobierno establece los puestos. La Ley del Servicio civil determina la clasificación de empleados por capacitación y escalafón.

$[\ldots]$

6. ¿Cuántas mujeres jefes de departamento administrativo hay? ¿Llegan a los altos puesto?

HONDURAS y EL SALVADOR: No hay más que en el ramo educativo.

MÉXICO: Si llegan, especialmente en las dependencias de asistencia social, Relaciones Exteriores,

Secretaría del Trabajo y Secretaría de Educación.

ESTADOS UNIDOS: Si llegan a los puestos de importancia, existe un 3\% de mujeres en ellos.

$[\ldots]$

8. ¿Hay diferencias de sueldos para el hombre y para la mujer en igual puesto?

HONDURAS: No.

EL SALVADOR: Según la Constitución, no.

MÉXICO y ESTADOS UNIDOS: Tampoco.

$[\ldots] .^{33}$

Sobre esa base estudiaron, también de manera comparativa, ${ }^{34}$ además de la situación de las empleadas fiscales u oficiales, la de las: obreras, trabajadoras a domicilio, obreras agrícola, empleadas particulares y mujeres profesionales e independientes; de igual modo abordaron: la problemática del trabajo doméstico y de la maternidad, las consecuencias económicas y sociales del trabajo de la mujer, la condición económica de la mujer trabajadora y las cuestiones sociales (problemas de nutrición, vivienda, abandono, salud, prostitución y prisiones para mujeres

33 "Primer Seminario Regional de la Comisión Interamericana de Mujeres. Tema III. Aspecto económico-social. Primera sesión", s. 1. s.f., en AHGE-SREM/APCL, Exp. 219. 34 Maldonado. 
menores) ${ }^{35}$

En general encontraron una serie de carencias en relación a leyes y reglamentos, así como en cuanto a aplicación de las existentes con vista a brindar la protección debida a las trabajadoras en sus diversas modalidades; de igual modo se hizo evidente la falta de educación y capacitación que permitiera a las mujeres acceder a algunos empleos y a ciertos niveles en ellos. Para lo que, también en forma general, propusieron propugnar por el establecimiento y el respeto de leyes laborales en las que se hiciera explícito la salvaguarda de los derechos femeninos en ese ámbito; de manera similar platearon la necesidad de que se fundaran y funcionaran escuelas y oficinas que orientaran y formaran a las mujeres en distintas profesiones, artes y oficios. ${ }^{36}$

En cuanto a un tema particularmente sensible para las mujeres en general y, en especial para las trabajadoras, como es la maternidad y el cuidado de los hijos, detectaron la siguiente problemática:

$1^{\circ}$ Resistencia para dar empleo y peligro de despido de trabajadoras para evitar indemnizaciones de maternidad.

$2^{\circ}$ Falta de clínicas prenatales, salas, cunas y guarderías.

$3^{\circ}$ Falta de educación sexual adecuada.

$4^{\mathrm{o}}$ Irresponsabilidad de los progenitores, con respecto a la procreación y cuidado de los hijos. ${ }^{37}$

Ante ese panorama, plantearon las siguientes soluciones: " $1^{\circ}$ El seguro social debe incluir beneficios para la maternidad y el pago de salario de descanso; $2^{\circ}$ Creación de la ley de maternidad

35 Farfán Cano, "Conclusiones de mesa VI"; Esperanza Colín C y Gudelia Gómez, delegadas de México al Seminario Regional de la CIM, "Tercer aspecto del temario. Mesa redonda del aspecto económico-social”, s.1., s.f., en AHGE-SREM, Exp. III-2082-1.

36 Farfán Cano, "Conclusiones de mesa VI"; Maldonado.

37 Farfán Cano, "Conclusiones de mesa VI". 
y creación del código de la infancia”. ${ }^{38}$

Por último abordaron lo que denominaron cuestiones sociales señalando:

$1^{\text {a }}$ Lucha sistemática en contra de la prostitución, mediante el fomento de nuevas fuentes de trabajo.

$2^{\text {a }}$ Elaboración de un plan de trabajo que permita orientar las actividades de las asociaciones femeninas, que se interesen en campañas moralizadoras y de rehabilitación.

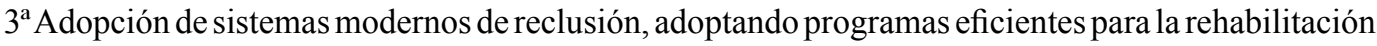
de los reclusos.

$4^{\mathrm{a}}$ Establecimiento de tribunales para menores y creación de instituciones conexas, en aquellos países donde no existen.

$5^{\text {a }}$ Que se hagan efectivas las leyes que sancionan las infracciones contra la moral en sus diversos aspectos.

$6^{\text {a }}$ Campaña antialcohólica $[\ldots] \cdot{ }^{39}$

\subsection{Aspecto educativo}

Las integrantes de la mesa redonda que tuvo a su cargo el análisis del aspecto educativo ${ }^{40}$ revisaron los siguientes subtemas: educación fundamental de las mujeres y aspectos específicos, como: habilidades y conocimientos básicos; salud, trabajo y familia; formación social, cívica y moral; empleo del tiempo libre; y aprovechamiento y conservación de los recursos naturales. También $38 \quad$ Ibid.

$39 \quad$ Ibid.

40 Isabel Farfán Cano, "Conclusiones de mesa redonda sobre educación pedagógica" (especial para los periódicos Lozano, VII), Magazín dominical de los periódicos Lozano, s.1., 27 de mayo de 1951 en AHDREM/ APACL, Exp. 222. Esta mesa estuvo presidida por Elena Echéverz, delegada de El Salvador; fungió como secretaria Margarita Chaparro Mena, también de El Salvador; y como relatora estuvo Guadalupe Ceniceros de Zavaleta, de México; las demás participantes fueron: Mercedes Maití de Luarca, de El Salvador; Estela Quezada Hernández de Costa Rica; María del Socorro Lacott de Estados Unidos; Consuelo de Escorcia de Honduras; y Sara Barquera de Nicaragua. 
examinaron: la educación vocacional, técnica y profesional; la educación para la vida familiar; la educación cívica; y la superación de las campesinas, las obrera y las trabajadoras domésticas. De igual modo abordaron los obstáculos que por razón del sexo se oponen a la educación de las mujeres; el papel que las instituciones escolares, culturales, cívicas, gremiales y profesionales en el mejoramiento de la educación de las mujeres; el aporte de éstas y de las organizaciones femeninas a la causa de la educación de las propias mujeres por medio de su influencia en el hogar; y su participación en las campañas educativas y su actividad profesional. ${ }^{41}$

En lo que respecta al primer y esencial punto de la educación fundamental de las mujeres, “[...] las delegadas adoptaron como principio básico 'que en todos los países se cumpla con la educación democrática estipulada en casi todas las constituciones de los países de América'. Educación que, según la U.N.E.S.C.O, 'tiene por objeto proporcionar a hombres y mujeres una vida más amplia y feliz, de acuerdo con su medio ambiente variable, desarrollará los elementos de su propia cultura y llevar a cabo el progreso económico y social que les permita ocupar el sitio al que tienen derecho en el mundo moderno, para realizar el anhelo de paz de las Naciones Unidas'. ."42

Sobre el mismo punto platearon un par de finalidades que jerarquizaron como inmediatas y otro par como mediatas. La primeras se expresaron en los siguientes términos: " $1^{\mathrm{a}}$ Enseñar a leer y escribir a las mujeres iletradas; y $2^{\mathrm{a}}$ Incorporar a la mujer a la educación fundamental". Las segundas se manifestaron así: " 1 a Afirmar principios de justicia y libertad; y $2^{\mathrm{a}}$ Defender al pueblo de la ignorancia". ${ }^{43}$

Adicionalmente platearon una serie de medidas concretas para la realización de este rubro de educación fundamental:

41 Farfán Cano, "Conclusiones de mesa VII"; "Resoluciones importantes".

42 Farfán Cano, "Conclusiones de mesa VII"; "Resoluciones importantes".

43 Farfán Cano, "Conclusiones de mesa VII"; "Resoluciones importantes". 
$1^{\circ}$ Preparar el ambiente indispensable, por todos los medios de divulgación posibles.

$2^{\circ}$ Pedir que en cada uno de los países se dediquen partidas del presupuesto para sostener económicamente la campaña alfabetizadora.

$3^{\circ}$ Crear misiones alfabetizadoras ambulantes o fijas.

$4^{\mathrm{o}}$ Exigir a los dueños de fábricas y fincas que proporcionen educación mínima a la mujer.

$5^{\circ}$ Que las leyes de alfabetización existentes ya en varios países, se respeten y cumplan.

$6^{\circ}$ Que en todos los países concurrentes se elabore una cartilla alfabetizadora, especialmente adaptada para la mujer.

$7^{\circ}$ Que en los países donde ya existen acuerdos, leyes, cooperación privada y propaganda en general, se intensifique la campaña alfabetizadora con ayuda de las organizaciones e instituciones femeninas.

$8^{\circ}$ Que en virtud de que la educación mínima que actualmente recibe la mujer, no la prepara debidamente para la vida, se incluyan en los programas de enseñanza elemental conocimientos que le permitan el desarrollo de funciones específicamente femeninas.

$9^{\circ}$ Que la educación fundamental de la mujer se complemente con lo siguiente: formación moral sólida, noción firme de la dignidad femenina, conocimientos higiénicos y cívicos, habilidades manuales que la capaciten para su función de futura ama de casa y madre de familia, a la vez, le proporcionen medios honrados de ganarse la vida y manera de utilizar los recursos naturales del medio donde se encuentra la escuela. ${ }^{44}$

Cada punto restante fue motivo de debate y de sugerencias. Para finalizar hicieron una propuesta que podría considerarse globalizadota y/o general sobre la necesidad de igualdad entre hombre y mujer en el aspecto educativo, en palabras de las delegadas quedó de la manera siguiente: “Que 44 Farfán Cano, "Conclusiones de mesa VII"; "Resoluciones importantes". 
se establezca una campaña sistematizada de persuasión a los padres de familia, autoridades y sociedad en general, respecto al derecho que tiene la mujer para actuar en los mismos campos que el hombre y, por consiguiente, a poder disfrutar de las mismas oportunidades que éste tiene en el campo de la educación". ${ }^{45}$

\section{Clausura y resultados}

Luego de varios días de intensa labor, el 2 de febrero tuvo lugar la última asamblea plenaria con la que se dio fin al seminario regional. ${ }^{46}$ En un primer balance, la presidenta de la CIM y organizadora del encuentro femenino señaló que las experiencias y los resultados habían sido múltiples, constructivos y estimulantes. ${ }^{47}$ Entre tanto, una de las delegadas mexicanas puso el acento en lo que no dudo en calificar de seriedad y solvencia científica y moral de sus homólogas de Estado Unidos y Centroamérica que participaron en cada uno de los cuatro grupos de trabajo, así como en el sentido de realidad que predominó en los debates, conclusiones y recomendaciones, con lo que se evitó "[...] el tan socorrido cause de la demagogia o cuando menos de la utopía". 48

En términos concretos se logró tener, como producto final, un amplio acervo que la misma presidenta de la CIM se comprometió a que dicho organismo resguardara y pusiera a disposición de las propias mujeres y de organizaciones femeninas, así como de los gobiernos y de organismos internacionales, como la misma CIM, con la finalidad de contribuir a un mejor conocimiento de 45 Guadalupe Ceniceros de Zavaleta, delegada de México al Seminario Regional de la CIM, "Cuarto aspecto del temario. Mesa redonda de asuntos educativos", s.l., s.f., en AHGESREM, Exp. III-2082-1.

46 Isabel Farfán Cano, "Mujeres de América. Clausura de las labores del Seminario Interamericano", (especial para los periódicos Lozano, VIII), Magazín dominical de los periódicos Lozano, s.l., 3 de junio de 1951 en AHDREM/APACL, Exp. 222.

47 de Castillo Ledón, "El Primer Seminario".

48 Lavalle Urbina, "Informe de las actividades". 
leyes y prácticas útiles y utilizables en beneficio de las mujeres. Es decir, se buscaba que ese material de consulta diera paso a nuevos y más amplios estudios, lo mismo que a la elaboración de planes de trabajo encaminados a mejor la situación femenina, en particular de la región donde se llevó a cabo el seminario. ${ }^{49}$

\section{Conclusiones}

A partir de la documentación consultada se ha podido, como se planteó en el objetivo de la ponencia, realizar un acercamiento a lo sucedido en el primer seminario regional organizado por la CIM en San Salvador, entre el 15 de enero y el 3 de febrero de 1951, en el que participaron representantes de los gobiernos de Estados Unidos, México y Centroamérica.

Tal acercamiento ha permitido conocer las reivindicaciones, los debates y las recomendaciones de la reunión regional, mismas que giraron en torno a cuatro temas de suma importancia para las mujeres y sus derechos, a saber: el civil, el político, el económico-social y educativo; cada uno de los cuales se dividió, a su vez, en subtemas no menos trascendentes.

También se pudo vislumbrar la metodología empleada por las CIM en el seminario, misma que se basó, por un lado, en cuestionarios preparados previamente por las organizadoras con la finalidad de lograr mayor precisión en el análisis; y, por otro, en el estudio comparativo de la situación prevaleciente en cada uno de los países participantes. Esto último permitió establecer diferencias y semejanzas. A partir de ello, las mujeres reunidas en la capital salvadoreña hicieron propuestas tanto para superar problemas que se presentaban en un determinado país en particular, como asuntos que afectaban al grueso de ellas en la región.

No es posible concluir la ponencia sin subrayar que, pese a los esfuerzos de la CIM en esta y otras actividades, las reivindicaciones, los debates y las recomendaciones del seminario de 49 de Castillo Ledón, "El Primer Seminario". 


\section{OI 9० CONGRESO \\ - $:$ CENTROAMERICANO \\ DE HISTORIA \\ Universidad de costa Rica}

Indexaciones: Repositorio de Revistas UCR, DIALNET, Latindex, REDALYC Directorio y recolector de recursos digitales del Ministerio de Cultura de España, Directory of Open Access Journals. Diálogos Revista Electrónica de Historia ISSN 1409-469X. Número especial 2008. Dirección web: http://historia.fcs.ucr.ac.cr/dialogos.htm

referencia no lograron concretarse en acciones contundentes de reconocimiento y respeto de los derechos femeninos en la región. Por tanto, muchos de los planteamientos hechos en esa reunión, celebrada a principios de 1951, siguen vigentes más de medio siglo después. 


\section{ANEXO 1}

\section{Agenda $^{50}$}

\section{Aspecto civil}

1. La mujer ante el derecho civil

2. Situación ante la ley

a) Derechos Civiles consignados en los Códigos

b) Deficiencias que se observan en tales ordenamientos

3. Situación real

a) Factores que se oponen al disfrute pleno de los derechos civiles

b) Obstáculos que impiden el avance de la mujer en esta materia

\section{Estudio comparativo}

a) De los derechos civiles de que disfruta la mujer en cada uno de los países representados en el Seminario.

b) De los métodos empleados para la consecución de tales derechos y de la conveniencia de recomendarlos a los países representados.

\section{Proposiciones}

a) Medidas que han de adoptarse para corregir las discriminaciones existentes

b) Medidas apropiadas para estimular el avance de la mujer y garantizar sus conquistas

50 "Agenda del Primer Seminario Regional de la Comisión Interamericana de Mujeres, San Salvador, El Salvador, Enero 15-31, 1951 ( sic)", s.1., s.f., en AHGH-SREM, Exp. III-2082-1; “Agenda” (versión preliminar), s.l., s.f., en AHSRE/APACL, Exp. 217. 
c) Tareas concretas de las organizaciones de mujeres para la realización de estas proposiciones

\section{Aspecto político}

1. La mujer ciudadana

2. Aportación de la mujer en la vida política y administrativa de América

3. Situación ante la ley

a) Derechos políticos consignados en los códigos

b) Deficiencias que se observan en tales ordenamientos

4. Situación real

a) Factores que se oponen al disfrute pleno de los derechos políticos

b) Obstáculos que impiden el avance de la mujer en esta materia

c) Participación de la mujer en los partidos políticos

5. Estudio comparativo

a) De los derechos políticos de que disfruta la mujer en cada uno de los países representados en el seminario

b) De los métodos empleados para la consecución de tales derechos y de la conveniencia de recomendarlos a los países representados

c) Estadísticas

6. Proposiciones

a) Medidas que han de adoptarse para corregir las discriminaciones existentes

b) Medidas apropiadas para estimular el avance de la mujer y garantizar sus 
conquistas

c) Tareas concretas de las organizaciones de mujeres para la realización de estas proposiciones

\section{Aspecto Económico y Social}

1. Las perspectivas de una nueva orientación económica mediante el trabajo de la mujer

2. Forma de cooperar para la realización del estudio sobre la situación económica de la mujer trabajadora en América, encomendado a la Comisión Interamericana de Mujeres por la Conferencia de Bogotá

\section{La mujer campesina}

a) Situación de la mujer campesina ante la ley y en la realidad

b) Aportación de la mujer campesina a los trabajos del campo y del hogar

c) Mejoramiento técnico para la mujer campesina

d) Medidas para proteger a la mujer campesina, buscando su mejoramiento en todos los órdenes

\section{La mujer obrera}

a) Situación de la mujer obrera ante la ley y en la realidad

b) La explotación del trabajo clandestino llamado "a domicilio"

c) Protección a la obrera en su calidad de madre: maternidades, guarderías, etc.

d) Discriminación a las obreras por razón de sexo

e) Planes a realizar para corregir toda discriminación y procurar el mejoramiento integral de la mujer obrera, teniendo en cuenta postulados universalmente aceptables, tales como "A igual trabajo, igual salario" 
f) Dificultades que confronta la mujer trabajadora en otras actividades

5. Dificultades que confronta la mujer trabajadora en otras actividades

a) Trabajadoras intelectuales

b) Empleadas oficiales

c) Empleadas particulares

d) El trabajo doméstico

6. Problema social del tráfico de personas y de la prostitución

7. Urgencia de crear Instituciones de tipo asistencial en beneficio de la mujer

a) Consultorios médicos

b) Maternidades

c) Guarderías infantiles

d) Jardines de niños

\section{Aspecto Educacional}

1. La escuela como factor de elevación para la mujer.

2. Aportación de la mujer a la causa de la educación en América.

3. Discriminaciones que sufre la mujer en materia de educación, por razón de sexo.

4. La educación rural, agente de mejoramiento en la comunidad.

5. Campaña de alfabetización.

6. Escuelas o internados dedicados especialmente para capacitar a las mujeres obreras o campesinas.

7. Preparación de la mujer para su función en el hogar.

8. Educación técnica, educación vocacional. 


\section{O月 $9^{\circ}$ CONGRESO \\ O 8 CENTROAMERICANO \\ DE HISTORIA}

Universidad de costa Rica

Indexaciones: Repositorio de Revistas UCR, DIALNET, Latindex, REDALYC Directorio y recolector de recursos digitales del Ministerio de Cultura de España, Directory of Open Access Journals.

Diálogos Revista Electrónica de Historia ISSN 1409-469X. Número especial 2008. Dirección web: http://historia.fcs.ucr.ac.cr/dialogos.htm

9. Formación de sensaciones de menos valía en la mujer, especialmente en la cultura latinoamericana.

10 Divulgación de la necesidad de equiparar la condición civil, política y social de la mujer a la del hombre.

11. Difusión en las escuelas, de la educación cívica, política y social de la mujer.

12. Organización de cursos breves de cívica para mujeres adultas.

13. Cursos para instruir a la mujer, sobre sus derechos; necesidad de despertar su interés por ejercitarlos.

14. Preparación para mejores empleos 


\title{
ANEXO 2
}

\section{Delegadas oficiales concurrentes al Seminario ${ }^{51}$}

\author{
Directora General del Seminario \\ Sra. Amalia de Castillo Ledón \\ Presidenta de la
}

CIM

\section{Estados Unidos}

Jefe de la Delegación: $\quad$ Jefe de la División Internacional de la

Miss Mary M. Cannon Oficina de a Mujer del Ministerio del Trabajo;

Delegada de los Estados Unidos a la

\section{CIM}

\section{México}

Jefe de la Delegación: $\quad$ Magistrado del Tribunal Superior de Justicia;

Abogada María Lavalle Urbina Delegada Alterna a la

CIM

\section{El Salvador}

51 de Castillo Ledón, "El Primer Seminario". Cabe apuntar que en el mismo documento está la relación completa de las participantes. 
Jefe de la Delegación: $\quad$ Delegada Titular de El Salvador a la

Srta. Esther Brizuela

CIM

Sra. Carmen Vilanova de Alfaro

Secretaría Ejecutiva del Comité de

Operación Salvadoreño a la

CIM.

\section{Honduras}

Jefe de la Delegación: $\quad$ Maestra de Enseñanza Primaria;

Srita. Olimpia Varela y Varela Catedrática del Instituto Normal de la Ceiba;

Directora de la Revista Pan-América.

Abogada Gertrudis Bográn de C. Sria. del Comité de Cooperación San Pedro a la

CIM;

Ex-Catedrática de la Universidad del

Estado de Louisiana y de la de Syracusse.

Profesora del Instituto Dptal de San Pedro.

\section{Nicaragua}

Jefe de la Delegación: $\quad$ Viceministro de Educación Pública.

Abogada Olga Núñez (de) Abaunaza Presidenta de la Asociación de Mujeres

Universitarias de Nicaragua

\section{Costa Rica}

Jefe de la Delegación: Profesora Normalista, Miembro de la Junta

Señora María Teresa de Dengo de Educación de San José de Costa Rica. 
Indexaciones: Repositorio de Revistas UCR, DIALNET, Latindex, REDALYC Directorio y recolector de recursos digitales del Ministerio de Cultura de España, Directory of Open Access Journals.

\section{CUADRO 1}

\section{Participantes}

\begin{tabular}{|l|l|}
\hline País & No. de representantes \\
\hline Estados Unidos & 4 \\
\hline México & 6 \\
\hline El Salvador & 18 \\
\hline Honduras & 4 \\
\hline Nicaragua & 4 \\
\hline Costa Rica & 3 \\
\hline Total & 39 \\
\hline
\end{tabular}

Elaboración propia con base en: Doc. mc., Amalia de Castillo Ledón, presidenta de la

CIM, "El Primer Seminario Regional de la Comisión Interamericana de Mujeres (15

de enero al 3 de febrero de 1951, El Salvador)", s.l., s.f., en AHSRE-SREM/APACL,

Exps. 207 y 219. 